\title{
Estimation of total, added and free sugar intakes in Japanese adults using a newly developed food composition database
}

Recently, sugar contents of foods were reported for the first time in the Standard Table of Food Composition in Japan 2015 (STFCJ). However, only one third of food items included sugar contents with no data for added and free sugar. We therefore estimated habitual intakes for total, added and free sugar in Japanese adults after we developed a comprehensive database based on STFCJ.

Apparently healthy workers aged 20-69 years (196 men and 196 women, mean BMI $23 \cdot 3 \mathrm{~kg} / \mathrm{cm}^{2}$ ) conducted 4-d weighed dietary records in 2013. Total sugar contents for foods with missing information in STFCJ were assigned using a data-gathering method ${ }^{(1)}$. Added and free sugar contents were assigned using a published 10-step method ${ }^{(2)}$. Of the 2222 food items in STFCJ, 2154 (96.9\%) were assigned for total sugar and $2212(99.5 \%)$ for added and free sugar. Habitual intakes were estimated using the Best-power $\operatorname{method}^{(3)}$.

Women had higher mean habitual intakes of total sugar (13.5 vs. 10.7 \% energy ( $\% \mathrm{E})$ ), added sugar (7.2 vs. 5.8 \% E), and free sugar $(7.4$ vs. $6 \cdot 1 \%$ E) than men, respectively (all p<0.0001; Figs. $1-3$ ). For free sugar intake (Fig. 3 ), $8.2 \%$ for men and $13 \cdot 3 \%$ for women exceeded the recommendation by WHO $(10 \% \mathrm{E}$ ), while the percentage of participants consuming $<5 \% \mathrm{E}$ (the WHO conditional recommendation and the UK recommendation) was $44.9 \%$ for men and $12.2 \%$ for women, respectively.

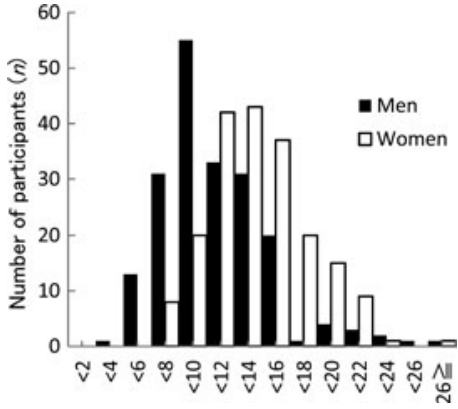

Fig. 1. Total sugar $(\% \mathrm{E})$

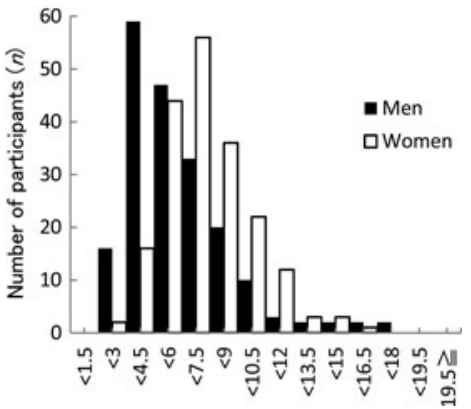

Fig. 2. Added sugar $(\% \mathrm{E})$

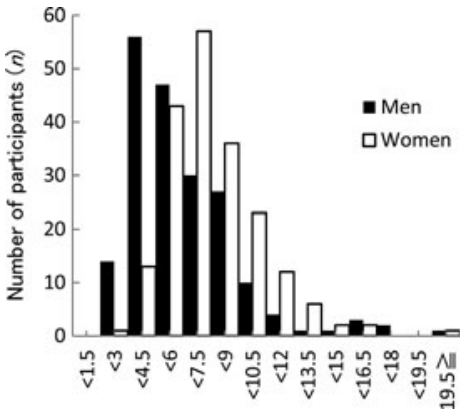

Fig. 3. Free sugar $(\% \mathrm{E})$

In conclusion, mean sugar intakes in this Japanese population were lower than those in Western countries $(14 \cdot 5-20 \cdot 2 \% \mathrm{E}$ for total sugar and $7 \cdot 3-13 \cdot 2 \% \mathrm{E}$ for added sugar $\left.{ }^{(4,5)}\right)$. Nevertheless, while the prevalence of excessive intake $(\geq 10 \% \mathrm{E}$ of free sugar) was low, there were only a few participants whose intake was within the recommended limit $(<5 \% \mathrm{E}$ of free sugar $)$, particularly in women.

1. Rand WM, Pennington JAT \& Murphy SP (1991) Compiling Data for Food Composition Data Bases. Tokyo: United Nation University Press.

2. Louie JCY, Moshtaghian H, Boylan S et al. (2015) Eur J Clin Nutr 69, 154-161.

3. Nusser SM, Carriquiry AL, Dodd KW et al. (1996) J Am Diet Assoc 91, 1440-1449.

4. Azaïs-braesco V, Sluik D, Maillot M et al. (2017) Nutr J 16, 6.

5. Ervin RB \& Ogden CL (2013) NCHS Data Brief 122 